\title{
Cyclosporine A - treated nephrotic children show impaired vasodilatation but no autonomic neuropathy
}

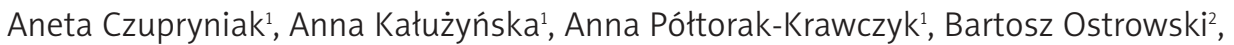
Bogusław Więcek², Marcin Tkaczyk ${ }^{1}$

1Division of Nephrology, Polish Mother's Memorial Hospital Research Institute of Lodz, Poland

2Institute of Electronics, Technical University of Lodz, Poland

Submitted: 14 April 2009

Accepted: 22 February 2010

Arch Med Sci 2010; 6, 4: 573-577

DOI: 10.5114 /aoms.2010.14470

Copyright @ 2010 Termedia \& Banach

\section{Abstract}

Introduction: The aim of the study was to determine the effect of long-term cyclosporine $A(C S A)$ treatment in children with idiopathic nephrotic syndrome on autonomic nerve function and peripheral blood flow assessed with thermography. Material and methods: The study group consisted of 19 nephrotic children treated with cyclosporine A compared to 16 healthy children. The assessment of blood flow was made based on the results of thermographic measurements during the cold stress test by an infrared radiation registering camera. Ewing's battery of non-invasive tests was used to assess autonomic function.

Results: The study showed diminished temperature increase after the cooling test in children with nephrotic syndrome treated with CsA. Sympathetic activity test results were comparable to healthy children.

Conclusions: It may be hypothesized that cyclosporine A administered even in low doses induces small vessel dysfunction measured by the thermographic method. This effect seems to be independent of sympathetic nervous system involvement, which was absent in cyclosporine A treated nephrotic children.

Key words: cyclosporine A, autonomic function, vasodilatation, thermography, children, nephrotic syndrome.

\section{Introduction}

Cyclosporine $A(C S A)$ is used routinely in the immunosuppressive regimen in children with both steroid-dependent and steroid-resistant nephrotic syndrome (SD-NS and SR-NS) [1-3]. However, its use is limited by adverse reactions, which include acute and chronic nephrotoxicity and hypertension $[4,5]$. Mechanisms by which CsA treatment leads to nephrotoxicity and hypertension are poorly understood. It has been shown that acute dosedependent CsA nephrotoxicity results from functional vasoconstriction of the afferent pre-glomerular arterioles followed by a decrease in renal blood flow [6]. Prolonged vasoconstriction causing chronic ischaemia may contribute to chronic CsA-dependent tubulointerstitial changes [4, 5, 7, 8]. The concept of CSA inducing hypertension through impairment of vascular regulatory mechanisms is still under debate.

Acute CsA-dependent impairment of peripheral blood flow presenting as Raynaud's phenomenon (RP) has recently been described by Arinsoy et al. and Sharma et al. $[9,10]$. Raynaud's phenomenon is a symptom of

\author{
Corresponding author: \\ Marcin Tkaczyk, MD PhD \\ Division of Nephrology \\ Department of Paediatrics \\ and Immunology \\ Polish Mother's Memorial \\ Hospital Research Institute \\ 281/289 Rzgowska St. \\ 93-338 Lodz, Poland \\ Phone: +48 422712140 \\ Fax: +48 422711091 \\ E-mail:mtkaczyk@uni.lodz.pl
}


cutaneous microvascular lesion related to disturbed local and/or systemic regulation of skin microcirculation. Blood flow in the microcirculation is controlled by three major elements: vascular smooth muscle cell tone, endothelial function and sympathetic innervation [11]. Cyclosporine A use was found to affect sympathetic nervous system activity as well as endothelial function $[5,7,12,13]$. Since sympathetic nerve activity is a major determinant of vascular tone, peripheral vascular function assessment should include measurements of both vascular reactivity and sympathetic activity [11]. To fully investigate the direct effect of CsA on these parameters the potential influence of administration of additional drugs should be excluded. However, steroids are used very frequently with CsA and complete removal should be avoided.

The aim of the study was to determine the effect of long-term CsA treatment in children with idiopathic nephrotic syndrome on peripheral blood flow as assessed with thermography and autonomic nerve function.

\section{Material and methods}

\section{Subjects}

The study group consisted of 19 children (11 M, $8 \mathrm{~F}$; mean age $10.8 \pm 4.4$ years) with mean duration

Table I. Selected clinical data from the cyclosporine A treated and healthy children

\begin{tabular}{|c|c|c|}
\hline Data & Study group & Controls \\
\hline Number of patients & 19 & 16 \\
\hline Male/female & $11 / 8$ & $10 / 6$ \\
\hline Age [years] & $10.8 \pm 4.4$ & $11.7 \pm 3.8$ \\
\hline $\mathrm{BMI}\left[\mathrm{kg} / \mathrm{m}^{2}\right]$ & $20.9 \pm 5.5$ & $18.5 \pm 2.6$ \\
\hline Systolic blood pressure [mmHg] & $118 \pm 11^{\star}$ & $112 \pm 3$ \\
\hline Diastolic blood pressure [mmHg] & $75 \pm 6^{*}$ & $71 \pm 3$ \\
\hline NS treatment [months] & $75.6 \pm 49.2$ & - \\
\hline eGFR $[\mathrm{ml} / \mathrm{min} / 1.73 \mathrm{~m} \mathrm{BSA}]$ & 128 & 135 \\
\hline CsA treatment [months] & $44.5 \pm 27.6$ & - \\
\hline Mean CsA [ng/ml] & $70.9 \pm 47.0$ & - \\
\hline Haemoglobin $[\mathrm{g} / \mathrm{l}]$ & $133 \pm 9$ & $136 \pm 11$ \\
\hline Albumin $[g / l]$ & $33 \pm 4$ & $35 \pm 5$ \\
\hline $\begin{array}{l}\text { Response to steroid therapy: } \\
\text { - steroid dependency } \\
\text { - steroid resistance }\end{array}$ & $\begin{array}{c}18 \\
1\end{array}$ & - \\
\hline $\begin{array}{l}\text { Histology at onset of NS: } \\
\text { - MCD } \\
\text { - FSGS }\end{array}$ & $\begin{array}{c}18 \\
1\end{array}$ & - \\
\hline $\begin{array}{l}\text { Nephrotoxicity on renal } \\
\text { biopsy [patients] }\end{array}$ & 2 & - \\
\hline Hypertension [patients] & $5^{*}$ & $0^{*}$ \\
\hline
\end{tabular}

* significantly different $v$ s. controls $p<0.05$ of nephrotic syndrome $6.3 \pm 4.1$ years. All subjects from the study group were treated with CsA for at least 6 months, mean $44.5 \pm 27.6$ months. Other medication included prednisone (30\% of patients, mean dose $0.5 \mathrm{mg} / \mathrm{kg} /$ day). Five patients in the study group were hypertensive and they were all treated with angiotensin-converting enzyme (ACE) inhibitors in monotherapy. Subjects with cardiovascular disease other than hypertension, postural hypotension, hypo- or hyperthyroidism, and intercurrent infection were excluded from the study.

All patients were in the remission of nephrotic syndrome defined by normal plasma albumin level with no proteinuria when the study procedures were performed.

Sixteen healthy age- and gender-matched children served as controls. The clinical characteristics of the groups are presented in Table I.

\section{Procedures}

\section{Thermographic imaging}

Vascular function studies were carried out in the morning after a 12-h fast. The assessment of blood flow was made based on the results of thermographic measurements during the cold stress test (CST). The infrared radiation registering device Inframetrics PM290 camera (Inframetrics Corp., Billerica, Mass., USA) was used for registration. Data acquisition and analysis were conducted using software prepared by the Institute of Electronics, Technical University of Lodz [14]. The software was used to calculate mean temperature in the predefined skin areas and temperature time trend projections, thus enabling precise temperature change assessment in various parts of the body.

The thermographic assessment was performed according to the method described by Ammer and Ring [14]. In short, a standard thermogram of the dorsal surface of both hands was recorded after 15-min equilibration in a draught-free room at a controlled temperature of $22^{\circ} \mathrm{C}$. The hands were then placed on a thin board at heart level. The CST was performed by covering the hands with gloves and immersing them into a large bowl of water at $20^{\circ} \mathrm{C}$ for $1 \mathrm{~min}$. Afterwards the temperature of both hands was recorded by infrared camera every $10 \mathrm{~s}$ for $10 \mathrm{~min}$. The metacarpal region and finger region were predefined for the purpose of temperature change assessment. Temperature recorded in the finger region was the mean for five fingers.

Peripheral blood flow disturbances were assessed with dynamic temperature changes registration and characterized as the temperature increase rate in the first 5 min after CST.

A gradient between the finger and metacarpal regions greater than $4^{\circ} \mathrm{C}$ after 10 min of CST was considered diagnostic for RP [15]. 


\section{Basic biochemistry}

Blood for biochemical assays was sampled in fasting conditions upon completion of vascular studies. Plasma was separated instantly at $4^{\circ} \mathrm{C}$ in a refrigerated centrifuge. In both groups serum creatinine, albumin, haemoglobin, cholesterol and urinary protein level were assessed using standard laboratory methods. Plasma creatinine concentration was used to estimate creatinine clearance according to the Schwartz formula. Whole blood CsA level was assessed using a non-specific radioimmunoassay.

\section{Autonomic function testing}

Cardiovascular autonomic function was assessed on the same day at least $2 \mathrm{~h}$ after the subjects had their meal. The following Ewing's battery of non-invasive tests was used [15]:

1. Blood pressure reaction to standing (orthostatic hypotension test). Blood pressure was recorded after 10 min of supine rest and after $2 \mathrm{~min}$ in the standing position. Reduction of minimum $20 \mathrm{mmHg}$ in systolic and minimum $10 \mathrm{mmHg}$ in diastolic pressure after standing up was considered diagnostic for orthostatic hypotension.

2. Heart rate response (HRR) to standing (30:15 ratio). The ECG monitoring was performed after a rest period in the supine position of $10 \mathrm{~min}$, starting from $1 \mathrm{~min}$ before until $30 \mathrm{~s}$ after standing. The ECG tracings were used to determine the $30: 15$ ratio calculated as the ratio of the longest $R-R$ interval found at about beat 30 to the shortest R-R interval found at about beat 15 .

3. Valsalva manoeuvre. The ECG monitoring was performed while the patient in supine position forcibly exhaled for $15 \mathrm{~s}$ against a fixed resistance (40 $\mathrm{mmHg}$ ) with open glottis. The ratio of the longest R-R interval after the manoeuvre to the shortest R-R interval during or shortly after the manoeuvre was calculated, and a ratio equal to or lower than 1.1 was considered abnormal.

4. Deep breathing test. The ECG monitoring was performed in supine position with the patient breathing deeply at a rate of 6 breaths/min. An average of 6 cycles was taken and the maximum (during inspiration) heart rate minus the minimum (during expiration) heart rate was calculated. The average difference found for 6 consecutive inspiration-expiration cycles was taken as the final result, with a value equal to or lower than $10 \mathrm{bpm}$ considered abnormal.

\section{Statistical analysis}

Statistical analysis was performed using the STATISTICA for Windows software package (version 5.5 PL, \#AXXP0105488425A55, StatSoft, Tulsa, Ohio, USA). For all analysed continuous parameters that showed a normal distribution (as confirmed with Kolmogorov and Lilliefors tests), differences between means were assessed by the Student's $t$-test for unpaired data. Differences in distribution were analysed by the non-parametric $\chi^{2}$ test, when necessary with Yates' correction. The measurements were expressed as means $( \pm \mathrm{SD})$. Values for $p<0.05$ were considered significant.

The study received approval from the local independent Ethics Review Board. Informed written consent was obtained (after careful explanation) from parents or caregivers and children when applicable (over 15 years).

\section{Results}

Finger region temperature increase within 5 min following CST was significantly diminished in children with nephrotic syndrome treated with CsA than in the control group $(0.26 \pm 0.26$ and 0.51 $\pm 0.29^{\circ} \mathrm{C} / \mathrm{min}, p=0.02$ ), while metacarpal region temperature change was similar in both groups. Temperature in both predefined hand regions $5 \mathrm{~min}$ after CST was stable in both groups.

Raynaud's phenomenon was found in three children ( 2 girls and 1 boy) from the study group and in 2 girls from the control group $(p>0.05)$. Not unexpectedly, the temperature gradient between finger and metacarpal regions after CST in patients with RP was $4.81 \pm 0.24$, while in study group subjects without RP it was $0.58 \pm 0.37(p<0.01)$. The temperature change after CST was similar in subjects with and without hypertension $\left(0.19 \pm 0.18\right.$ vs. $0.38 \pm 0.36^{\circ} \mathrm{C} / \mathrm{min}$, respectively; $p=0.23$ ).

No significant differences in autonomic function tests were found between study and control groups. In detail, the test results were: Orthostatic hypotension test was positive for 4 patients in the study and 3 subjects in the control group $(p=0.79)$. The mean slope of blood pressure did not differ significantly (systolic: $15 \pm 5$ vs. $13 \pm 3 \mathrm{~mm} \mathrm{Hg}$; diastolic $7 \pm 3$ vs. $8 \pm 2 \mathrm{mmHg}, p: 0.05)$. The results of HRR test $30: 15$ index (1.24 \pm 0.19 vs. $1.33 \pm 0.2)$, Valsalva manoeuvre (1.59 \pm 0.35 vs. $1.84 \pm 0.53)$ and E : I index (1.46 \pm 0.24 vs. $1.45 \pm 0.17)$ were also not different; all $p>0.05$.

The mean dose of CsA was $4.3 \pm 1.6 \mathrm{mg} / \mathrm{kg}$. At the time of the study mean plasma CsA in the study group was $70.9 \pm 26.0 \mathrm{ng} / \mathrm{ml}$, with concentration from the 6-month period before the study $85.7 \pm 40.1 \mathrm{ng} / \mathrm{ml}$. No statistically significant correlation between CsA or steroid treatment duration or dose and temperature change after CST was found. Similarly, no correlation between plasma CsA and biochemical parameters or hand warming indices was noted either. Results of laboratory measurements are summarized in Table I. 


\section{Discussion}

Impaired endothelial function has been postulated as a link between accelerated atherosclerosis and NS [16, 17]. Children with NS are known to present with vascular complications much more often than the general population. Interestingly, there have been no studies assessing the peripheral circulation in NS; however, it was found that sympathetic hyperreactivity often accompanies proteinuric renal diseases [18]. The defective baroreflex control over renal sympathetic nerves might also be related to impaired renal sodium handling $[18,19]$. Amongst the wide range of drugs prescribed in NS only CSA has been reported to directly influence endothelium and sympathetic activity and raise blood pressure by these pathways $[5,12]$.

In our study, the rate of temperature change in fingers after CST was significantly lower in NS patients treated with CsA than in healthy children, which suggests that the peripheral circulation is impaired in this group of subjects.

The microcirculation damage in the study group was not severe enough to increase prevalence of RP, a symptom of significant vascular regulation impairment [20, 21]. This may result from either the young age of the patients or relatively low doses of CsA used due to its toxicity. Sharma et al. reported a case of a post-renal transplant patient in whom RP always occurred at the time of CSA dose increase and when plasma CsA concentration exceeded $300 \mathrm{ng} / \mathrm{ml}$. Dose reduction and plasma CsA below $200 \mathrm{ng} / \mathrm{ml}$ led to RP resolution [10].

Static measurements of temperature distribution cannot serve as an objective examination as they considerably depend on the temperature of the surroundings. That was the reason why we applied a dynamic method of constant temperature registration after cooling the hands that detects even small but significant disturbances of blood flow.

Apart from the destructive effect of NS on vasculature, CSA treatment may additionally distort vascular regulation. Lucini et al. and Stein et al. reported similar findings in patients treated with CsA after heart transplantation and with rheumatoid arthritis [5, 22]. Stein et al. found that CsA directly impaired vascular vasodilation through endothelium-related pathways rather than affecting nervous regulation [22].

Both sympathetic and parasympathetic parts of the autonomic nervous system are involved in vascular regulation. Ewing's battery has long been used as a reliable tool for autonomic nervous function assessment. Heart rate variability with deep breathing, heart rate response to Valsalva manoeuvre and heart rate response to standing (30 : 15 ratio) verify mostly parasympathetic function, and blood pressure response to standing assesses sympathetic adrenergic function [11]. However, no relation between autonomic nervous system activity and microcirculation impairment in NS children was found. Both NS and CSA treatment may exert an effect on peripheral nerves, but in NS patients only the intrarenal sympathetic nervous system function was disturbed and was closely related to the renal sodium handling $[8,18,23]$. A distinct influence of CSA on renal and extrarenal small vessel reactivity was observed in transplanted rats by Gabriëls et al. [24].

Previous studies have reported on CsA-related neurotoxicity within the autonomic nervous system, while in contrast a recent publication questioned the role of increased sympathetic activity in the CsA-induced blood pressure rise [13, 22]. It seems that the doses of CSA routinely used in children and adolescents are probably too low to have a significant detrimental effect on autonomic nervous system activity [12]. Cyclosporine A nephrotoxicity depends on its vasoconstricting effect on afferent glomerular arterioles [7]. It was found that CsA decreased mRNA synthesis of nitric oxide synthase in rodents and induced direct endothelial damage [25]. These mechanisms might be responsible for CsA-induced hypertension. In our study group we had 5 children (26\%) with hypertension, when in other studies the percentage of hypertensive children among CsA-treated patients varied from $10 \%$ to $12 \%$ [1]. Perhaps this increase may be related to longer CsA treatment (44 m vs. 34 or 22 in other studies) [1].

Many non-invasive techniques have been developed to measure arterial and peripheral blood flow in humans. The thermographic methods applied in our study were less invasive than ultrasound brachial artery relaxation in response to transient ischaemia applied in adult patients [26]. Thermography has become a standard indirect measurement in diagnosis of RP as painless and easily analysed [14]. It was observed that the changes in superficial hand temperature correlated positively with small vessel reactivity and furthermore might be applied to assess endothelial dysfunction [27].

Our study, however, has some limitations. The number of studied patients was relatively small, and drawing unequivocal conclusions from our experiment would be premature. Moreover, we have not studied children with NS but not treated with CsA, which if we had would have enabled us to precisely discern between the vascular damaging impact of NS and CSA treatment. However, one reason for that was the fact that at our centre nowadays few children with steroid-dependent (similar by clinical classification) NS are not treated with CSA. We tried to reduce this bias by qualifying 
children with low dose steroid treatment, but it should be strongly taken into consideration in the clinical interpretation and should force further detailed investigation. Other drugs with a proven influence on endothelium and sympathetic activity were excluded ( $\beta$-blockers, ACE inhibitors).

In conclusion, the results of our study suggest that in children with nephrotic syndrome treated with CsA administered in low doses small vessel dysfunction as measured with the novel and valuable thermographic method is detected. This effect seems to be independent of sympathetic nervous system involvement, which was absent in cyclosporine A treated nephrotic children.

\section{References}

1. El-Husseini A, El-Basuony F, Mahmoud I, et al. Long-term effects of cyclosporine in children with idiopathic nephrotic syndrome: a single-centre experience. Nephrol Dial Transplant 2005; 20: 2433-8.

2. Seikaly MG, Prashner H, Nolde-Huribert B, Browne R. Long-term clinical and pathological effects of cyclosporin in children with nephrosis. Pediatr Nephrol 2000; 14: 214-7.

3. Iyengar A, Karthik S, Kumar A, Biswas S, Phadke K. Cyclosporine in steroid dependent and resistant childhood nephrotic syndrome. Indian Pediatr 2006; 43: 14-9.

4. Fujinaga S, Kaneko K, Muto T, Ohtomo Y, Muarakmi H, Yamashiro $Y$. Independent risk factors of chronic cyclosporine-induced nephropathy in children with nephrotic syndrome. Arch Dis Child 2006; 91: 666-70.

5. Lucini D, Milani RV, Ventura HO, Mehra MR, Messerli F, Pagani M. Study of arterial and autonomic effects of cyclosporine in humans. Hypertension 2000; 35: 1258-63.

6. Lucini D, Milani RV, Ventura HO, et al. Cyclosporineinduced hypertension: evidence for maintained baroreflex circulatory control. J Heart Lung Transplant 1997; 16: 615-20.

7. Gossmann J, Radounikli A, Bernemann A, et al. Pathophysiology of cyclosporine-induced nephrotoxicity in humans: a role for nitric oxide? Kidney Blood Press Res 2001; 24: 111-5.

8. Elzinga LW, Rosen S, Burdmann EA, Hatton DC, Lindsley J, Bennett WM. The role of renal sympathetic nerves in experimental chronic cyclosporine nephropathy. Transplantation 2000; 69: 2149-53.

9. Arinsoy T, Derici U, Yuksel A, Reis KA, Sindel S. Cyclosporine-a treatment and a rare complication: Raynaud's phenomenon. Int J Clin Pract 2005; 59: 863-4.

10. Sharma AK, Sunil S, Rustom R, et al. Cyclosporin A related Raynaud's phenomenon in a renal transplant recipient. Transpl Int 2002; 15: 517-8.

11. Freeman R. Autonomic peripheral neuropathy. Lancet 2005; 365: 1259-70.

12. Bechstein WO. Neurotoxicity of calcineurin inhibitors: impact and clinical management. Trasplant Int 2000; 13: 313-26.

13. Hausberg M, Lang D, Levers A, et al. Sympathetic nerve activity in renal transplant patients before and after withdrawal of cyclosporine. J Hypertens 2006; 24: 957-64.

14. Ring E, Ammer K, Jung A, et al. Standardization of infrared imaging. Conf Proc IEEE Eng Med Biol Soc 2004; 2: 1183-5.
15. Ewing DJ, Clarke BF. Diagnosis and management of diabetic autonomic neuropathy. Br Med J (Clin Res Ed) 1982; 285: 916-8.

16. Tkaczyk M, Owczarek D, Nowicki M. Tissue plasminogen activator (tPA) and its inhibitor (PAI-1) concentrations in cyclosporine A-treated children with idiopathic nephrotic syndrome. Pol Merkuriusz Lek 2003; 79: 134-6.

17. Tkaczyk M, Czupryniak A, Owczarek D, Lukamowicz J, Nowicki M. Markers of endothelial dysfunction in children with idiopathic nephrotic syndrome. Am J Nephrol 2008; 28: 197-202.

18. Camici M. Nephrotic proteinuria and the autonomic nervous system. Saudi J Kidney Dis Transpl 2007; 18: 512-2.

19. Dibona GF, Jones SY, Sawin LL. Reflex influences on renal nerve activity characteristics in nephrosis and heart failure. J Am Soc Nephrol 1997; 8: 1232-9.

20. Czupryniak A, Kałuzyńska A, Nowicki M, Wiecek B, Bald E, Owczarek D. Raynaud's phenomenon and endothelial sysfunction in end-stage renal disease patients treated with hemodialysis. Kidney Blood Press Res 2005; 28: 27-31.

21. Block JA, Sequeira W. Raynaud's phenomenon. Lancet 2001; 357: 2042-8.

22. Stein CM, He H, Pincus T, Wood AJ. Cyclosporine impairs vasodilation without increased sympathetic activity in humans. Hypertension 1995; 26: 705-10.

23. Lucini D, Milani RV, Ventura HO, Mehra MR, Messerli F, Pagani M. Study of arterial and autonomic effect of cyclosporine in humans. Hypertension 2000; 35: 1258-63.

24. Gabriëls G, August C, Grisk O, et al. Impact of renal transplantation on small vessel reactivity. Transplantation 2003; 75: 689-97.

25. Lessio C, de Assunção Silva F, Glória MA, et al. Cyclosporine $A$ and NAC on the inducible nitric oxide synthetase expression and nitric oxide synthesis in rat renal atrery cultured cells. Kidney Int 2005; 68: 2508-16.

26. Jourdan C, Wühl E, Litwin $M$, et al. Normative values for intima media thickness and distensibility of large arteries in healthy adolescents. J Hypertens 2005; 23: 1707-15.

27. Kharalkar N, Volvano JW. Analysis of a thermal method for assessing endothelial dysfunction. Biomed Sci Instrum 2004; 40: 86-92 